\title{
FORMAÇÃO DO PROFESSOR DE EDUCAÇÃO FÍSICA: COERÊNCIAS E INCOERÊNCIAS
}

José Jailton da Cunha ${ }^{1}$, Maria Lucineide Dioginis ${ }^{2}$, Fernando Henrique Neves ${ }^{2}$, Nívea Cristina Lucindo $^{3}$, Wilson Cristovam ${ }^{4}$

${ }^{1}$ Faculdade Anhanguera Educacional. ${ }^{2}$ Diretoria de Ensino de Mirante do Paranapanema. ${ }^{3}$ Universidade do Oeste Paulista - UNOESTE, Presidente Prudente, SP. ${ }^{4}$ Secretaria da Educação do Estado de São Paulo. E-mail: comissaodeesportes@terra.com.br

\section{RESUMO}

O presente trabalho teve como objetivo realizar uma investigação a respeito da formação dos professores de Educação Física buscando analisar as coerências e contradições com relação à formação do professor. A pesquisa de abordagem qualitativa do tipo estudo de caso procurou identificar na Proposta Pedagógica de um curso de Educação Física de uma Universidade do interior do Estado de São Paulo, os elementos que favorecem ou não a formação do professor. $O$ trabalho foi realizado por meio de contatos diretos com os sujeitos envolvidos nos espaços que trabalham, através de entrevistas e análise documental. Os resultados sugerem que a proposta pedagógica da licenciatura investigada apresenta certa coerência com os documentos oficiais no momento da sua elaboração, porém, a sua implementação coloca em evidência incoerências que podem influenciar a formação do profissional capacitado para atuar na área da Educação Física. Palavras-chave: Educação Física; Formação de professores; Pedagogia.

\section{FORMATION OF THE PHYSICAL EDUCATION TEACHER: CONSISTENCIES AND INCONSISTENCIES}

\begin{abstract}
This study aimed to conduct an investigation regarding the training of physical education teachers seeking to analyze the consistencies and inconsistencies with relationship teacher training. A qualitative study of the type of case study sought to identify the pedagogical proposal of a Physical Education course at a university in the state of São Paulo, the factors that encourage or discourage the education of teachers. Data were analyzed from the perspective of qualitative research as having the theoretical support for analysis of the content. The results suggest that the pedagogical proposal of the investigated bachelor's degree exposes a certain coherency with official documents when elaborated, but is implementation shows clearly incoherencies that can influence a skilled professional to work in the area of Physical Education.
\end{abstract}

Keywords: Physical Education; Teacher Education; Educational Policy Project 


\section{INTRODUÇÃO}

Este trabalho tem sua origem pautada nas preocupações decorrentes da ação docente na área da educação física em relação à formação do professor, buscando relacionar a teoria com a prática na aplicabilidade docente.

Segundo os Parâmetros Curriculares Nacionais - PCNs - (BRASIL, 1997), atualmente, a busca por uma Educação Física que contribua para a formação das pessoas revela que, além das concepções de corpo e movimento, também é necessário desenvolver as dimensões cultural, social, política e afetiva dos seres humanos, pois estes interagem e se movimentam como sujeitos sociais e como cidadãos.

Sendo assim, o presente trabalho teve como objetivo geral, analisar o Projeto Político Pedagógico de um curso de licenciatura em Educação Física, a fim de compreender as coerências e contradições com relação à formação do professor.

Os objetivos específicos do trabalho consistiram em identificar, na Proposta Pedagógica do Curso os elementos que favorecem ou não a formação do professor e analisar, a partir das falas dos sujeitos envolvidos na formação do professor de Educação Física, os elementos que favorecem e/ou que dificultam esse processo de formação.

A justificativa para a implementação da pesquisa teve origem na falta de interesse que se tem observado comumente por parte dos alunos em participar de atividades que envolvem a Educação Física.

Esta pesquisa foi aprovada pelo Comitê de Ética e Pesquisa (CEP) com o número do protocolo $027 / 09$.

As preocupações com atividades de Educação Física bem orientadas levaram à proposição de uma investigação qualitativa do tipo estudo de caso, cujo objetivo foi verificar se a Proposta Pedagógica contemplada em um Curso de Formação de Professores de Educação Física oferece ao licenciado conhecimentos, habilidades e atitudes que lhe possibilitem desenvolver ações em sala de aula coerentes com as orientações atuais da área, proporcionando, assim, formação adequada e suficiente para o momento atual.

Este trabalho procurou mostrar como está sendo a formação do profissional para atuar na licenciatura da Educação Física, analisando os elementos que favorecem e/ou dificultam a formação do professor.

Diante destes questionamentos, esta comunicação apresentará os seguintes tópicos: A formação e profissionalização docente; a formação específica do professor de Educação Física e a importância da construção do Projeto Político Pedagógico na Licenciatura de Educação Física, e 
também os dados referentes às análises de um Projeto Político Pedagógico, buscando compreender as coerências e incoerências em relação a formação do licenciado em Educação Física.

\section{A formação e Profissionalização Docente}

Ao analisar a questão da formação docente, Perrenoud (2000) salienta que uma das qualidades marcantes dos professores é o otimismo, acompanhado do respeito à capacidade das crianças e dos adolescentes para exercerem suas responsabilidades.

Segundo o referido autor "[...] o ofício do professor consiste, também, em administrar a progressão das aprendizagens e envolver os alunos em suas aprendizagens e em seu trabalho" (PERRENOUD, 2000, p. 13).

Para que estas ações se efetivem, os professores precisam ter uma formação de qualidade, adequada às suas necessidades profissionais, conforme seus contextos sociais, e que reflita, posteriormente, na qualidade do ensino deste profissional.

A formação na Licenciatura envolve discussão de questões a respeito de ações que vão além do âmbito da sala de aula. São tarefas de planejamento, organização curricular, elaboração de programas direcionados à melhoria do ensino e da instituição educativa.

Desta forma, o professor precisa adquirir, na graduação, não só conhecimentos e habilidades, mas também deve se envolver em atividades de trabalhos de grupos, nas quais aprende a resolver problemas, adquirindo uma nova concepção de seu trabalho no seu contexto, o que não é possível sem o envolvimento de todos.

A formação assume um papel que vai além do ensino que pretende uma mera atualização científica, pedagógica e didática e se transforma na possibilidade de criar espaços de participação, reflexão e formação para que as pessoas aprendam a se adaptarem para conviver com a mudança e a com a incerteza. (IMBERNÓN, 2002, p. 15).

Para Imbernón (2002), a inovação das instituições educativas não pode ser proposta sem que se tenha outro conceito de profissionalização docente que rompa com as práticas do passado, assumidas apenas como elementos intrínsecos à profissão. O professor não deve ser um técnico, mas converter-se em um profissional que tenha participação ativa e crítica no processo de inovação e mudança dentro do seu próprio contexto, por meio de um método dinâmico e flexível, e a própria instituição deve ser o local apropriado para essa mudança.

O autor aponta, ainda, que ser um profissional da educação significa participar da emancipação das pessoas, ajudando a torná-las livres, menos dependentes do poder econômico, 
político e social.

Nas próximas décadas a profissão deverá desenvolver-se em uma sociedade em mudança, com um alto nível tecnológico e um vertiginoso avanço do conhecimento. Isso implica não apenas a preparação disciplinar, curricular, mediadora, ética, institucional, coletiva, mas também uma importante bagagem cultural assim será necessária formar o professor na mudança e para a mudança. (IMBERNÓN, 2002, p. 33).

Ao analisar a problemática do processo de formação docente, Schön (1995) coloca que este processo deve propiciar aos professores conhecimentos, habilidades e atitudes para se desenvolverem como profissionais reflexivos e investigadores. Nesta linha, o eixo fundamental do currículo de formação do professor é o desenvolvimento da capacidade de refletir sobre a própria prática docente, com o objetivo de aprender a interpretar, compreender e refletir sobre a realidade social e a docência.

Assim, a formação inicial proporciona ao professor o conhecimento e a interpretação de situações complexas, além de envolver os professores em formação comunitária para contribuir com a realidade social e estabelecer modelos intelectuais.

Para Imbernón (2002), de uma forma geral, a formação inicial recebida pelos professores não oferece preparo suficiente para o desenvolvimento de novas proposições para a sala de aula. Além disso, eles não têm informações necessárias sobre como desenvolver, implantar e avaliar processos de mudanças. Porém, essa informação inicial é importante e se configura como um período em que as intenções, os vícios, as rotinas são assumidas como processos iniciais da profissão.

De acordo com Abdalla (2006, p. 94), a formação do professor envolve um conhecer permanente:

[...] da exploração, da experimentação, das trocas de experiências, do esforço para passar da ignorância ao conhecimento. É o conhecer da aprendizagem de conhecer mais e melhor, do aprender a ensinar e a ser professor de determinados saberes. Saberes que se traduzem pela compreensão que fazemos da prática docente, de aprender e apreender o significado da situação didática, o espaço das relações pedagógicas e a refletir junto sobre as formas desse conhecimento, revitalizando os processos humanos em fluxo.

Os professores, segundo Abdalla (2006), sentem necessidade de complementação de sua formação envolvendo a aprendizagem cooperativa, participativa, em uma cultura colaborativa. A coordenação pedagógica e a direção da escola precisam assumir uma intencionalidade, definir o perfil de mudança, de progresso desejado, proporcionar na equipe motivações de mudanças e crescimento, gerando novas práticas. 
Entender a escola como contexto de ação e de formação do professor implica competência em instituir práticas socioculturais e institucionais, ou seja, saber organizar, saber gerir, saber mobilizar as pessoas, tendo consciência de que essa prática são processos formativos. (ABDALLA, 2006, p. 13).

É neste contínuo que os professores aprendem a conhecer a escola e a cultura organizacional, a discutir o seu trabalho coletivamente e a estabelecer relações comunicativas, e com isso, se habilitam a intervir nas mudanças organizacionais da escola.

Abdalla (2006) ressalta, ainda, que a unidade dialética entre as práticas de gestão e as práticas de formação continuada é muito importante no processo de formação, pois as pessoas aprendem com as organizações e as organizações aprendem com as pessoas, nesse mesmo processo de troca de conhecimentos.

É importante assinalar que a escola caracteriza-se por ser um campo de conflitos e interesses, de mudanças formais e informais para se conseguir poder, já não se trata de controlar a escola por imposições burocráticas, mas de permitir que haja participação de toda a comunidade, tanto em relação aos aspectos de sua organização, quanto às tomadas de decisão. (ABDALLA, 2006, p. 57).

\section{A formação específica do Professor de Educação Física}

De acordo com Wachowicz (1981), a formação de profissionais para a Educação Física é bastante deficiente no Brasil. Os cursos de formação funcionam em condições precárias, com currículos desajustados às necessidades de desenvolvimento do setor, e com corpo docente sem a preparação necessária.

Embora a prática regular da Educação Física nas $1^{\text {as }}$ séries do 10 grau ${ }^{1}$ seja quase inexistente no país, existe uma controvérsia sobre qual profissional deva ser responsável pela Educação Física nessas séries: se o professor especialista, ou o professor polivalente/regente de classe. A esse respeito Araújo (1983, p. 55) lembra que:

Antes a Educação Física era realizada pela mesma professora que em geral era leiga em Educação Física e hoje já temos o professor de Educação Física trabalhando essas jovens crianças para que as mesmas possam começar a descobrir os movimentos e a sua relação

Aragão e Carmo (1983) enfatizam que muitos dos problemas que envolvem o processo de ensino-aprendizagem em Educação Física estão relacionados com a formação do professor desse componente curricular. Os autores associam esses problemas, entre outros fatores, à baixa

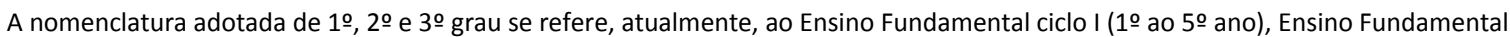
ciclo II (6 ao 9ano), Ensino Médio, respectivamente.
} 
solicitação, durante os cursos de licenciatura, das categorias intelectuais de conhecimento e síntese, impedindo, desse modo, que o aluno utilize as informações recebidas, trabalhe com elaborações pessoais, efetue análises, capacite-se para lidar com situações, detecte e resolva problemas atinentes à área, e posicione-se criticamente. Assim, quando no exercício de sua profissão, o docente restringe-se à reprodução do que obteve em nível de informações, sem autonomia e de forma acrítica.

\section{A importância da construção do Projeto Político Pedagógico na licenciatura em Educação Física}

Para que a construção do Projeto Político Pedagógico seja possível não é necessário convencer os docentes, a equipe escolar e os funcionários a trabalhar mais, ou mobilizá-los de forma espontânea, mas propiciar situações que lhes permitam aprender a pensar e a realizar o fazer pedagógico de forma coerente.

Nessa perspectiva, o Projeto Político Pedagógico vai além, ou seja, possibilita a melhor articulação das ações desenvolvidas pela escola, o diálogo necessário para sua elaboração como uma maior aproximação com a realidade e a construção de uma proposta que seja marcada de fato, pela identidade do grupo. (VASCONCELLOS, 2002, p. 17).

Segundo Vasconcellos (2002), o Projeto Político Pedagógico tem uma importante contribuição no sentido de ajudar a conquistar e consolidar a autonomia da escola, criar um clima, um ethos, no qual professores e equipe se sintam responsáveis por aquilo que lá acontece, inclusive em relação ao desenvolvimento dos alunos. De certa forma, é o PPP que vai articular, no interior da escola, a desestabilização e a quebra de paradigma do professor e permitir o diálogo consistente e fecundo com a comunidade e com os órgãos dirigentes.

Neste sentido, o Projeto Político Pedagógico na IES pode se constituir numa sistematização de um trabalho participativo, coletivo e cooperativo que define as ações de todos os sujeitos envolvidos.

\section{Analisando o Projeto Político Pedagógico de um curso de licenciatura em Educação Física}

O presente estudo envolveu pesquisa bibliográfica, pesquisa documental e trabalho de campo com a realização de entrevistas com coordenador, professores e alunos de uma instituição formadora de professores de Educação Física.

Neste trabalho optou-se pela abordagem qualitativa, do tipo estudo de caso, caracterizada por permitir contatos diretos com os sujeitos envolvidos e os espaços pesquisados com relação ao problema apresentado. 
Conforme Minayo (1994, p. 22),

A pesquisa qualitativa responde as questões muito particulares. Ela se preocupa, nas ciências sociais, com um nível de realidade que não pode ser quantificado. Ou seja, ela trabalha com o universo de significados, motivos, aspirações, crenças, valores e atitudes, o que corresponde a um espaço mais profundo das relações, dos processos e dos fenômenos que não podem ser reduzidos a operacionalização de variáveis.

O principal instrumento de coleta de dados deste estudo foi a entrevista semiestruturada, pois a:

Entrevista semi-estruturada é aquela que parte de certos questionamentos básicos, apoiados em teorias e hipóteses, que interessam à pesquisa e que, em seguida, oferecem amplo campo de interrogativas, junto de novas hipóteses que vão surgindo à medida que recebem as respostas do informante. Desta maneira o informante, seguindo espontaneamente a linha de seu pensamento e de suas experiências dentro do foco principal colocado pelo investigador, começa a participar na elaboração do conteúdo da pesquisa. (TRIVIÑOS, 1987, p. 145).

$\mathrm{Na}$ instituição pesquisada, as disciplinas pedagógicas aparecem com pouca freqüência e tardiamente na grade curricular, e os estágios supervisionados também aparecem apenas no 4 은 termo e com carga horária insignificante.

No decorrer das análises das respostas dos entrevistados e na análise da grade curricular, foi possível constatar que os estágios supervisionados não acontecem desde o início do curso, o que pode comprometer a relação teoria e prática que se busca em todo curso de formação profissional.

É importante ressaltar, também, que o curso pesquisado apresenta, na sua estrutura curricular, uma formação distribuída em seis semestres letivos, o que totaliza um período de três anos, sendo assim, um período de tempo relativamente curto, deixando a desejar na formação voltada para a licenciatura, já que se utiliza de um leque menor de disciplinas pedagógicas, podendo comprometer a formação.

Em relação à atuação dos professores que lecionam no curso pesquisado, foi possível observar que existe um aproveitamento do corpo docente, inclusive alguns chegam a ministrar várias disciplinas, mesmo que sua formação não seja adequada para tais, e isto também pode ser considerada uma incoerência que compromete a formação dos graduandos.

Vale ressaltar, ainda, que a formação acadêmica dos professores que formam os novos licenciados para atuar na Educação Física Escolar com foco voltado para a licenciatura, apresenta, de modo geral, um caráter extremamente tecnicista, o que pode deixar lacunas na formação em 
relação ao aspecto pedagógico.

Outro fator bastante significativo em relação às incoerências na formação proposta por esta IES, está ligado à questão dos estágios supervisionados, que são organizados e direcionados por professores cuja formação apresentada em seu currículo não atende os conceitos para orientar os estágios, uma vez que os mesmos possuem apenas formação específica e não pedagógica, comprometendo a prática docente e criando, assim, uma indissocialidade entre teoria e prática, fator este que compromete a formação.

Apenas um dos professores entrevistados atua nas disciplinas que se relacionam à sua formação, não comprometendo a formação e nem abrindo lacunas para o apontamento de incoerências.

Foi possível perceber, também, que todos os professores entrevistados realizaram trabalhos de conclusão de curso direcionados para o treinamento desportivo de rendimento, e somente na pós-graduação foi que um dos entrevistados apontou em seu currículo um trabalho com foco na ação docente.

\section{CONSIDERAÇÕES FINAIS}

A formação do Professor de Educação Física é de suma importância, considerando que a disciplina faz parte da Grade Curricular da Escola. Assim, esta disciplina contribui na formação integral do ser humano, elementos estes que se concretizam em relação à ação docente do professor.

Afirma-se então, que para a prática docente do Professor de Educação Física seja coerente com os propósitos elencados, o mesmo necessita conhecer o Projeto Político Pedagógico da instituição, bem como participar da construção, planejamento e elaboração dos planos de aulas.

Neste sentido, pode-se afirmar que a instituição analisada, apesar de apresentar uma proposta de licenciatura coerente com os documentos oficiais, deixa a desejar no que diz respeito à formação a que se propõe, pois a teoria não está comprometida com a prática, e não possibilita a busca de uma Educação Física que contribua para a formação do licenciando, que além das concepções de corpo e movimento esteja comprometida com a dimensão cultural, social, política e afetiva dos seres humanos, pois estes interagem e se movimentam como sujeitos sociais e como cidadãos (BRASIL, 1997).

\section{REFERÊNCIAS}

ABDALLA, M. F. B. O senso prático de ser e estar na profissão. São Paulo: Cortez, 2006. 
ARAUJO, R. de. O papel do professor de educação física na sociedade. Boletim da Federação Internacional de Educação Física, Brasília, v. 53, n. 4, p. 47-59. 1983.

ARAGAO, R. de; CARMO, A. A. do. Aspectos críticos de uma formação acrítica. Cadernos do CEDES, Campinas, v. 1, n. 8, p. 32-37, 1983.

BRASIL. Secretaria de Educação Fundamental. Parâmetros Curriculares Nacionais: Educação Física. Brasília/DF: MEC/SEF, 1997.

IMBERNÓN, F. Formação docente e profissional: formar-se para a mudança e a incerteza. São Paulo: Cortez, 2002.

MINAYO, M. C. S. (Org.). Pesquisa social, teoria, método e criatividade. Petrópolis: Vozes, 1994.

PERRENOUD, P. Dez novas competências para ensinar. Porto Alegre: Artes Médicas Sul, 2000.

SCHÖN, D. A. Formar professores como profissionais reflexivos. In: NÓVOA, A. Os Professores e sua Formação. Lisboa: Dom Quixote, 1995. P. 77-91.

TRIVIÑOS, A. N. S. Introdução à pesquisa em ciências sociais: a pesquisa qualitativa em educação. São Paulo: Atlas, 1987.

VASCONCELLOS, C. S. Coordenação do trabalho pedagógico: do Projeto Político Pedagógico ao cotidiano da sala de aula. São Paulo: Libertad, 2002. 212 p.

WACHOWICZ, L. A. A formação do educador. Educação e Sociedade, São Paulo, n. 9, p. 169-173, 1981. 